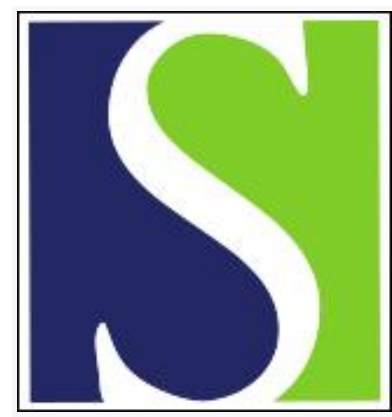

Scand J Work Environ Health 2015;41(1):24-35

https://doi.org/10.5271/sjweh.3468

Published online: 13 Nov 2014, Issue date: 01 Jan 2015

The role of ability, motivation, and opportunity to work in the transition from work to early retirement - testing and optimizing the Early Retirement Model

by de Wind A, Geuskens GA, Ybema JF, Bongers PM, van der Beek AJ

Previous studies identified determinants of early retirement, but little is known about how determinants influence early retirement (ie, underlying mechanisms). Testing an Early Retirement Model based on the literature showed that health, job characteristics, skills, and social factors influenced the transition from work to early retirement via a lower ability and opportunity to work.

Affiliation: TNO, Department of Work, Health \& Care, Schipholweg 77-89, 2316 ZL Leiden, The Netherlands. astrid.dewind@tno.nl

Refers to the following texts of the Journal: 2009;35(1):1-5 2014;40(2):186-194

The following articles refer to this text: 2017;43(1):34-41; 2017;43(4):326-336; 2022;48(4):312-321

Key terms: early retirement; Early Retirement Model; LISREL; motivation; opportunity to work; structural equation modeling; work ability

This article in PubMed: www.ncbi.nlm.nih.gov/pubmed/25393088

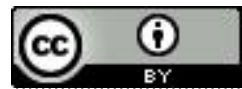




\title{
The role of ability, motivation, and opportunity to work in the transition from work to early retirement - testing and optimizing the Early Retirement Model
}

\author{
by Astrid de Wind, MSc, , 2, 3 Goedele A Geuskens, PhD, ${ }^{2}$ Jan Fekke Ybema, PhD, 2 Paulien M Bongers, \\ $P h D,{ }^{1,2,3}$ Allard J van der Beek, PhD 1,3
}

\begin{abstract}
de Wind A, Geuskens GA, Ybema JF, Bongers PM, van der Beek AJ. The role of ability, motivation, and opportunity to work in the transition from work to early retirement - testing and optimizing the Early Retirement Model. Scand J Work Environ Health. 2015;41(1):24-35. doi:10.5271/sjweh.3468
\end{abstract}

\begin{abstract}
Objectives Determinants in the domains health, job characteristics, skills, and social and financial factors may influence early retirement through three central explanatory variables, namely, the ability, motivation, and opportunity to work. Based on the literature, we created the Early Retirement Model. This study aims to investigate whether data support the model and how it could be improved.
\end{abstract}

Methods Employees aged 58-62 years ( $N=1862)$, who participated in the first three waves of the Dutch Study on Transitions in Employment, Ability and Motivation (STREAM) were included. Determinants were assessed at baseline, central explanatory variables after one year, and early retirement after two years. Structural equation modeling was applied.

Results Testing the Early Retirement Model resulted in a model with good fit. Health, job characteristics, skills, and social and financial factors were related to the ability, motivation and/or opportunity to work (significant $\beta$ range: $0.05-0.31$ ). Lower work ability $(\beta=-0.13)$ and less opportunity to work (attitude colleagues and supervisor about working until age $65: \beta=-0.24$ ) predicted early retirement, whereas the motivation to work (work engagement) did not. The model could be improved by adding direct effects of three determinants on early retirement, ie, support of colleagues and supervisor $(\beta=0.14)$, positive attitude of the partner with respect to early retirement $(\beta=0.15)$, and not having a partner $(\beta=-0.13)$.

Conclusions The Early Retirement Model was largely supported by the data but could be improved. The prolongation of working life might be promoted by work-related interventions focusing on health, work ability, the social work climate, social norms on prolonged careers, and the learning environment.

Key terms LISREL; structural equation modeling; work ability.

In the Netherlands, as in many other countries, the population is ageing due to the increase in life expectancy and decrease in fertility rate. This causes a pressure on the social security system and an expected shortage of workers in some sectors (1). Therefore, there is a societal need for workers to prolong their working life. Several pension system reforms have been implemented, targeting different pillars of the pension system. The Dutch pension system consists of three pillars: the state old-age pension, supplementary pension schemes by virtue of the employer or sector (about $90 \%$ of all employees), and private savings (2). The statutory retirement age at which persons receive their state old-age pension was for example raised from 65 years in 2012 to 67 in 2023 (3). Besides, fiscal measures made early retirement schemes by the employer or sector financially less attractive (4).

At the time of this study, statutory retirement age was still 65 years, and most employees still had access to extensive early retirement schemes. Dutch employers did relatively little to recruit and keep older workers compared to employers in, for example, Denmark,

1 Department of Public and Occupational Health, the EMGO+ Institute for Health and Care Research, VU University Medical Center, Amsterdam, The Netherlands.

2 Netherlands Organisation for Applied Scientific Research TNO, Hoofddorp, The Netherlands.

3 Body@Work, Research Center on Physical Activity, Work and Health, TNO-VU/VUmc, Amsterdam, The Netherlands.

Correspondence to: Astrid de Wind, TNO, Department of Work, Health \& Care, Schipholweg 77-89, 2316 ZL Leiden, The Netherlands. [E-mail: astrid.dewind@tno.nl] 
Germany, and Italy (5). In 2012, only $27 \%$ of employers reported it is important for staffing that employees continue working until the statutory retirement age (6). However, legislation protects older workers against age discrimination (7).

In previous research, a variety of factors influencing (non-disability) early retirement have been identified. Two systematic literature reviews reported that selfperceived poor health predicts early retirement with risk estimates ranging from 1.28-3.36, whereas having a musculoskeletal disorder or a respiratory disease did not $(8,9)$. Others found that depressive symptoms also predict early retirement (10).

Besides health, job characteristics may predict early retirement. High physical work demands, ie, extreme bending of the neck, predicted early retirement in one study [odds ratio (OR) 6.8] (11), but no significant relationship was found in other studies (OR ranging from $0.9-1.1)(12,13)$. High work pressure increased the likelihood of early retirement [hazard ratio (HR) 1.1] (13). Employees who experienced high appreciation at work were less likely to retire early $(\mathrm{OR}=0.58)$. A qualitative study showed that a poor social climate, ie, conflicts at work, influenced the process towards early retirement (14). Besides, skills and knowledge may influence early retirement. Provision of and participation in education and training was associated with reductions in intention to retire early and actual retirement behavior $(15,16)$. Persons with a higher focus on development of knowledge and skills also appeared less likely to retire (17).

Social factors may play a role in early retirement as well. Lund et al (11) found that having a partner increased the likelihood of early retirement (OR 2.8). Others added that partner support for continuing to work and retiring early predicted, respectively, retirement at older age and early retirement $(17,18)$. A longitudinal study showed that pension systems offering more generous retirement options were associated with higher rates of early retirement (19).

Other studies have shown that financial aspects might be a reason for not taking early retirement (20) and that the financial possibility to retire early strongly contributed to early retirement (17). Hence, factors in the domains of health, job characteristics, skills and knowledge, and social and financial factors may influence the transition from work to (non-disability) early retirement. As Schultz proposed, these factors can be seen as "push and pull" factors (21). Push factors are defined as negative circumstances that lead to early retirement. Poor health or high physical work demands may fall within this category. Pull factors are defined as positive factors that attract an individual towards early retirement, such as having a partner to spend more time with (21).

Qualitative research suggested that the ability, motivation, and opportunity to work mediate the relation- ship between determinants in the domains health, job characteristics, skills and knowledge, and social and financial factors, on the one hand, and early retirement on the other hand $(14,22,23)$. For example, employees experiencing physically demanding work or high work pressure retired early because they felt their work demands reduced their ability to continue working (14). Also, employees who experienced that their health problems impaired their ability to function at work, retired early $(22,23)$. Conflicts at work and continuous changes in the way work needed to be done resulted in a decreased motivation to continue working, and this in turn resulted in early retirement (14). Employees with poor health retired early because they felt pushed out by their employer, and hence, experienced a reduced opportunity to work (23).

Based on the literature, the research framework of the Dutch longitudinal Study on Transitions in Employment, Ability and Motivation (STREAM) was developed (24). According to this framework, determinants in the domains health, job characteristics, skills and knowledge, and social and financial factors influence work productivity and transitions in employment status through three central explanatory variables (ie, the ability, motivation, and opportunity to work). The ability to work refers to the concept of work ability (25). The motivation to work refers to both intrinsic and extrinsic motivations to work and work values and their fulfillment. The opportunity to work refers, for example, to support at work for continuing employment. Figure 1 shows the framework applied to early retirement (ie, the Early Retirement Model). To our knowledge, this model is the first of its kind to integrate both determinants and mechanisms underlying early retirement.

Although several studies identified determinants of early retirement, how determinants influence early retirement has barely been studied in quantitative research. More insight into mechanisms underlying early retirement could be helpful to develop effective interventions that promote continued employment until higher ages. Therefore, in the present study the Early Retirement Model was studied. Our first research question was: Do data support the Early Retirement Model? We hypothesized that all determinants described in Figure 1 influence the ability, motivation, and opportunity to work and that these variables in turn influence early retirement. For example, health is associated with work ability (26-28) and decreased work ability is a predictor of early retirement (29). In addition, social support is associated with a higher motivation to work $(30,31)$, and a lower motivation to work is associated with early retirement (32).

Our second research question was: How could the Early Retirement Model be improved? We explored whether direct relations between determinants and early retirement improved the Early Retirement Model, eg, if 


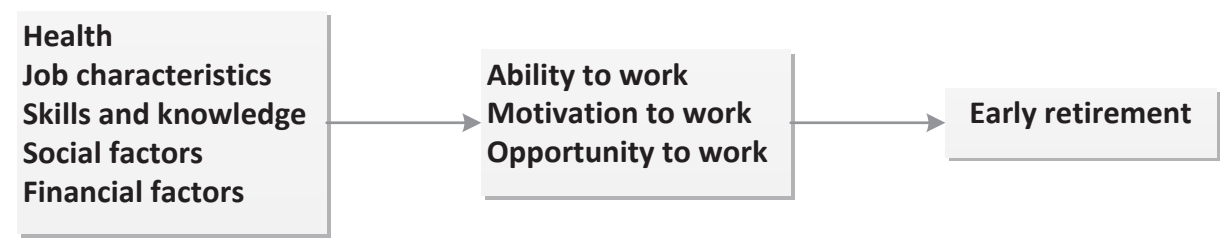

Figure 1. Early Retirement Model [based on the Study on Transitions in Employment, Ability and Motivation (STREAM) research framework] (24). factors other than the ability, motivation, and opportunity to work underlie the relation between determinants and early retirement.

\section{Methods}

\section{Study population}

The study population consisted of STREAM participants. STREAM is a Dutch longitudinal study among 15118 persons including employees $(\mathrm{N}=12$ 055), selfemployed persons $(\mathrm{N}=1029)$, and persons without paid employment $(\mathrm{N}=2034)$ aged $45-64$ years. The study population of STREAM was previously described in detail elsewhere (24). In short, persons participated in the internet panel of GfK Intomart, a company specialized in market research. The study population was stratified by employment status and age. Within the age groups 45-49, 50-54, 55-59, and 60-64 years, we aimed for the population to be representative of the Dutch population with respect to gender and educational level. Participants of STREAM completed online questionnaires annually in October / November 2010 (T1), 2011 (T2), 2012 (T3), and 2013 (T4). Participants were paid to complete a questionnaire, ie, for every completed questionnaire, the savings balance of the participant was increased by about $€ 3.00$. In the present study, we used data of the first three waves of STREAM.

Persons were included in the present study if they were employee at baseline and after one year of followup and aged 58-62 years at baseline. We chose 58 years as a lower age limit since the proportion of employees that had retired early strongly increased from this age onwards after two years of follow-up. We chose 62 years at baseline as the upper-age limit because the official retirement age was 65 years in the Netherlands at the time of the study. Hence, after two years of follow-up, the participants had not yet reached the official retirement age. Persons who indicated they were (partially) work disabled or unemployed at baseline, or after one or two years of follow-up, were excluded from the present study. Previous studies suggested that different factors and processes underlie these transitions out of work (33). Moreover, persons with missing information on one of the variables were excluded from the present study.
In total, 1862 persons were included (figure 2). Of the employees participating at T1, 84\% participated again at $\mathrm{T} 2$ and $75 \%$ at $\mathrm{T} 3$. To investigate whether loss to follow-up was selective, we compared baseline characteristics of respondents who participated in all measurements and those who did not. At baseline, persons lost to follow-up were slightly younger (59.7 versus 59.9 years, $\mathrm{P}<0.05)$, reported a slightly poorer mental health score $(52.7$ versus $53.5, \mathrm{P}<0.05)$ and higher focus on development of knowledge and skills (score 3.9 versus $3.8, \mathrm{P}<0.05)$, more often had no partner $(29 \%$ versus $23 \%, \mathrm{P}<0.05)$, and more often had a partner who did not work $(61 \%$ versus $56 \%, \mathrm{P}<0.05)$.

\section{Measurements}

Participants completed a yearly online questionnaire. Information on determinants, ie, demographics, health, job characteristics, skills and knowledge, and social and financial factors was derived from the baseline questionnaire. Information on the ability, motivation, and opportunity to work was derived from the questionnaire after one year of follow-up. The outcome variable "early retirement" was derived from the questionnaire after two years of follow-up.

\section{Determinants of early retirement}

Information on age, gender and educational level was available. Educational level was measured using a question on the highest level of education completed with a diploma, and categorized into low (primary school, lower and intermediate secondary education, or lower vocational training), intermediate (higher secondary education, or intermediate vocational training) or high (higher vocational education or university).

Perceived health was measured using the physical component summary (PCS) and mental component summary (MCS) scales of the Short Form-12 Health Survey (version 1). The scales range from 0 (worst possible health status) to 100 (best possible health status) (34).

Physical job demands were measured using a 6-item scale on regular use of force, the use of vibrating tools, awkward postures, prolonged standing, and prolonged squatting based on the Netherlands Working Conditions Survey (35) and the Dutch Musculoskeletal Questionnaire (36) (Cronbach's alpha 0.86). The 5-point response 
scale to these items (eg, "Does your job require that you stand for long periods of time?") ranged from "always" to "(almost) never". Job demands were measured with four questions derived from the Job Content Questionnaire (Cronbach's alpha 0.87). Responses to these items [ie, "Do you have to work very fast?" $(37,38)]$ were on a 5-point scale ranging from "always" to "(almost) never". Social support of colleagues and the supervisor was measured using four items derived from The Copenhagen Psychosocial Questionnaire (COPSOQ) (39) (Cronbach's alpha 0.81). Employees indicated how often their colleagues or their supervisor helped or supported them and how often they were willing to listen to their work-related problems. The 5-point response scale to these items (eg, "How often do you get help and support from your colleagues?") ranged from "always" to "almost never". Higher scores reflect higher social support from colleagues and the supervisor. In addition, participants indicated on a 4-point scale (ranging from "not present at all" to "highly present") whether appreciation was present at work (35).

In the domain of skills and knowledge, developmental proactivity was measured using a 4-item scale derived from Van Veldhoven and Dorenbosch (40). This scale reflects the extent to which persons actively search for activities in their job that allow them to expand knowledge and skills, and the extent to which persons adapt their knowledge and skills to (future) changes in their jobs. The 5-point response scale ranged from "totally disagree" to "totally agree"; Cronbach's alpha was 0.81 . A higher score reflects a higher focus on development of skills and knowledge.

With respect to social factors, participants provided information on their household composition. In the analyses, we distinguished between persons with and without a partner. If a person had a partner, the respondent reported the support of this partner with respect to early retirement with one item, ie, "What would your partner think if you would stop working completely as soon as you get the opportunity?" (18). Responses were on a 5-point scale, ranging from 1 ("very unpleasant") to 5 ("very pleasant"). If someone did not have a partner, we granted the mean population score on this variable to this person, following the missing value procedure by Cohen and Cohen (41). Also, the partner's employment status was assessed. In the analyses, we distinguished between non-working and working. If someone did not have a partner, we coded this as a non-working partner for further analysis, which was corrected for by including the variable for (not) having a partner to the analysis. In addition, the following life events in the past 12 months were assessed: death of a partner, death of a close family member or friend, partner got a serious disease, and a close family member or friend got a serious disease. In the analyses, we distinguished between persons who reported at least one of these life events and persons who did not.

In the domain of financial factors, the financial situation of the household was measured using the following item: "What is the financial situation of your household now?". Responses were: "very short of money", "somewhat short of money", "some money left" and "a lot of money left". In the analyses, we considered the financial situation of the household as a continuous variable. A higher score reflects a better financial situation of the household.

\section{Central explanatory variables}

We operationalized the motivation to work as work engagement. This concept was measured by means of two dimensions of the Utrecht Work Engagement Scale (UWES) (42): "vigor" (three items) and "dedication" (three items). Vigor refers to having a lot of energy at work and mental resilience, feeling strong and fit, and not getting tired from work very fast (eg "At my job, I feel strong and vigorous"). Dedication refers to enthusiasm, inspiration, pride, and job satisfaction (eg, "I am enthusiastic about my job"). The dimensions vigor and dedication were combined to one scale for work engagement (Cronbach's alpha 0.93). Items could be answered on a 7-point scale (ranging from "never" to "always"), with a higher score reflecting a higher work engagement.

The ability to work was measured with the following item of the Work Ability Index: "By 'work ability', we mean the degree to which you are able to work, both physically and mentally. If you assign ten points to your work ability in the best period of your life, how many points would you assign to your work ability at this moment?" The answer scale ranged from 0-10 (25).

The opportunity to work was operationalized by means of two variables, ie, age discrimination and attitude of colleagues and supervisor about working until age 65. Age discrimination was measured using three items derived from the Nordic Age Discrimination Scale on discrimination of older compared to younger workers with respect to opportunities for promotion, education and training, and development (43). These items (eg, "Elderly workers do not have equal opportunities for training during work time") could be answered on a 5 -point scale (ranging from "totally disagree" to "totally agree") and Cronbach's alpha was 0.87 . The attitude of colleagues and supervisor about working until age 65 was assessed using two items, ie, "Do your colleagues think it is important that you continue working until the official retirement age?" and "Does your supervisor think it is important that you continue working until the official retirement age?" (18). Items were answered on a 5-point scale ("very unimportant" to "very important", and "don't know"). We granted the mean population 
score to employees with both items missing or a "don't know" response $(16.8 \%)$. If persons had missing information or "don't know" on one of the items, we granted the score on the other item to these employees. In the analyses we considered the attitude of colleagues and supervisor as a continuous variable, with a higher score reflecting a more positive attitude of colleagues and supervisor about working until age 65 .

\section{Outcome}

Information on early retirement was derived from one question asking persons to indicate their employment status. In this study, early retirement referred to employees who retired before the official retirement age of 65 years. This definition excluded persons who indicated that they had retired but were still working as an employee or self-employed person.

\section{Analysis}

In order to test and improve the Early Retirement Model, structural equation modeling (SEM) was applied. SEM is in many respects similar to ordinary regression analyses. It tests the associations between one or more independent variables and one or more dependent variables. Independent variables are called exogeneous variables, and include only variables that are not influenced by other variables in the model, ie, demographics in our model. Dependent variables are called endogeneous variables, and include the outcome variable early retirement, but also the determinants and central explanatory variables as they all may be influenced by exogenous variables and / or by other endogenous variables. The big advantage of SEM above ordinary regression analyses is that it deals simultaneously with multiple relationships between exogeneous variables and endogeneous variables. The interpretation of the findings is very similar to ordinary linear regression analyses. Structural equation modeling provides standardized betas for the relations between pairs of variables, that usually vary from -1, which means perfect negative association, through 0 , which means no association at all to +1 , which means a perfect positive association. When performing SEM a researcher specifies a model about expected relations between several variables. Since we only used observed variables, a path model was constructed.

We used a robust maximum likelihood estimation, with correction of the standard errors of the estimates for non-normal distributions by using the asymptotic covariance matrix (44). First, we tested the Early Retirement Model. The hypothesized pathways within our model are presented in figure 3 . We specified a model with relations between determinants (T1) and central explanatory variables (T2), and between central explanatory variables
(T2) and early retirement (T3). We assumed no direct relations between determinants and early retirement. In these analyses, we controlled for the demographics age, gender, and educational level as assessed at T1. Secondly, we improved the Early Retirement Model. This step was explorative, and aimed to investigate whether direct relations between determinants and early retirement would contribute to the model. Improving the model took place in three steps: (i) we added direct relations between determinants and early retirement to the Early Retirement Model; (ii) we removed relations between determinants and central explanatory variables, determinants and early retirement, and central explanatory variables and early retirement with $\mathrm{P}>0.20$ all at once; and (iii) we removed all relations with $\mathrm{P}>0.05$ one-by-one by means of backward selection. In the final model we only kept significant relations $(\mathrm{P}<0.05)$.

Model fit was assessed using four different fit indices, based on recommendations by Hooper et al (45) and $\mathrm{Hu}$ and Bentler (46): model fit was evaluated with $\mathrm{X}^{2}$, root mean square error of approximation (RMSEA), standardized root mean square residual (SRMR), and comparative fit index (CFI). Model fit was considered to be good if: RMSEA $<0.05, \mathrm{SRMR}<0.05$, and $\mathrm{CFI} \geq 0.90$.

We used SPSS (IBM Corp, Armonk, NY, USA) for calculating descriptive statistics, and preparing a dataset that could be used in LISREL and PRELIS. LISREL is an application for structural equation modeling. PRELIS is a related application that, among others, computes covariance matrices for the purpose of analyses in LISREL. PRELIS was used to calculate a covariance matrix (relations between all variables) and an asymptotic covariance matrix for the purpose of analyses in LISREL.

\section{Ethical issues}

The Medical Ethical Committee of the VU University Medical Centre Amsterdam declared that the Medical Research Involving Human Subjects Act does not apply to STREAM. The Medical Ethical Committee had no objection to the execution of this study. In the information for participants that accompanied the online questionnaire, it was emphasized that the privacy of participants was guaranteed, all answers to the questions were treated confidentially, and all data were stored in secured computer systems.

\section{Results}

Table 1 shows the characteristics of the study population. Employees with the following professions were included: craft and industrial professions (5.7\%), transport professions $(4.3 \%)$, office clerks $(16.4 \%)$, commer- 


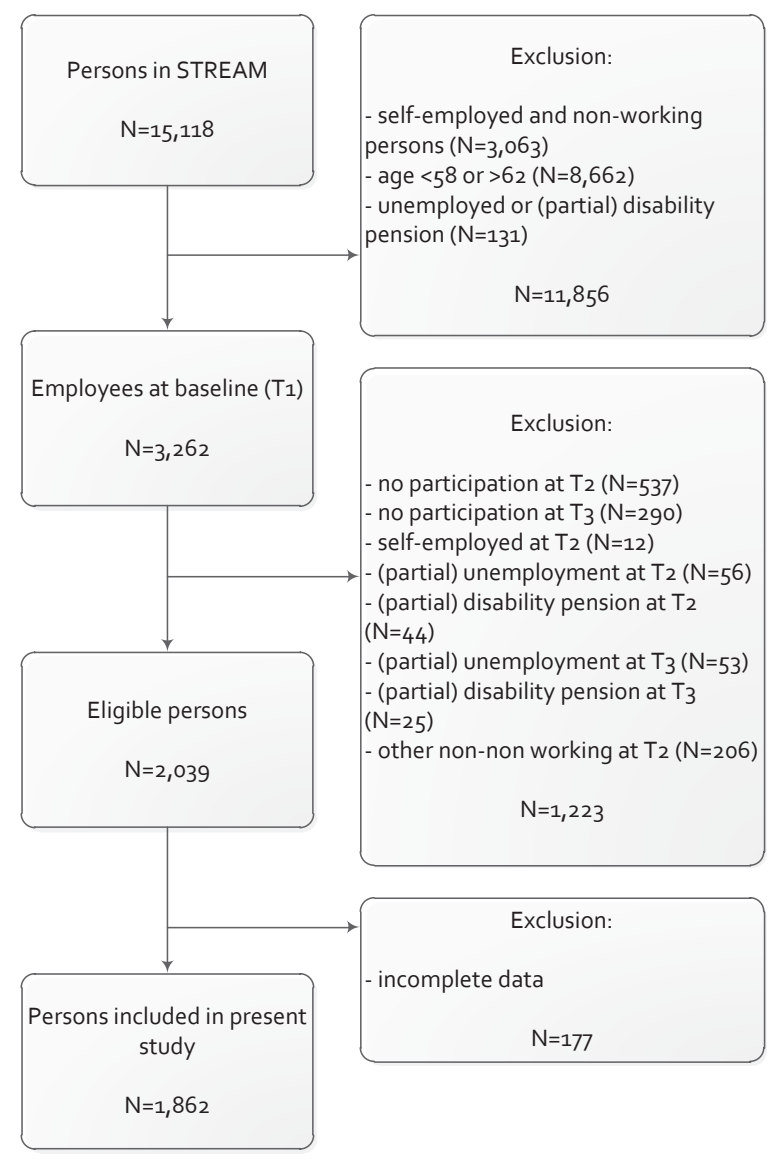

Figure 2. Study population. [STREAM= Study on Transitions in Employment, Ability and Motivation.]

cial professions $(5.7 \%)$, service professions $(8.3 \%)$, professions in health care and assistance (14.0\%), teacher/ lecturer $(10.1 \%)$, specialists $(8.6 \%)$, agricultural workers $(0.6 \%)$, executive staff $(9.2 \%)$, and other professions $(17.0 \%)$. In total $11.9 \%$ of the employees made the transition from work to early retirement between T2 and T3 $(\mathrm{N}=221)$. In general, the correlation between determinants was small to moderate $(0.01-0.23)$. A stronger association was found between appreciation at work and social support of colleagues and supervisor (Pearson's $r=0.43$ ). The correlation between central explanatory variables was small to moderate (Pearson's $r$ range: $0.13-0.36)$.

\section{Test of Early Retirement Model}

Testing the Early Retirement Model resulted in a model with an overall fit $\left(\mathrm{X}^{2}\right)$ of 180.96 with 12 degrees of freedom. The RMSEA, SRMR, and CFI measures (0.031, 0.018 , and 0.97 , respectively) indicated a good fit.
Therefore, the Early Retirement Model was considered to be a good model. The explained variance of early retirement in this model was $\mathrm{r}^{2}=0.19$. Table 2 shows that better physical and mental health were related to higher work engagement, higher work ability, less age discrimination, and a positive attitude of colleagues and supervisor about working until age 65. Higher physical demands were related to lower work ability and a less positive attitude of colleagues and supervisor about working until age 65 . Higher job demands were related to higher work engagement, more age discrimination, and a positive attitude of colleagues and supervisor about working until age 65 . Social support of colleagues and supervisor was related to higher work engagement and less age discrimination. More appreciation at work was related to higher work engagement, less age discrimination, and a positive attitude of colleagues and supervisor about working until age 65. A higher focus on development of knowledge and skills was related to higher work engagement, higher work ability, more age discrimination and a positive attitude of colleagues and supervisor about working until age 65 . A positive attitude of the partner with respect to early retirement was related to lower work ability, more age discrimination, and a less positive attitude of colleagues and supervisor about working until age 65 . A better financial situation of the household was only significantly related to less age discrimination at work. In addition, table 2 shows that employees with a higher work ability and a positive attitude of colleagues and supervisor about working until 65 less often retired early. Work engagement and age discrimination were not related to early retirement.

\section{Improved model}

Improving the Early Retirement Model resulted in an overall fit $\left(\mathrm{X}^{2}\right)$ of 93.72 with 39 degrees of freedom. The RMSEA, SRMR, and CFI measures were $0.0027,0.012$, and 0.99 respectively, and hence, indicated a good fit. Therefore, the improved model was considered to be a good model. The explained variance of early retirement in this model was $r^{2}=0.25$. Table 3 shows that the Early Retirement Model could be improved by adding direct effects of determinants on the outcome early retirement. Persons who reported higher support of colleagues and supervisor and persons who reported that their partner had a positive attitude with respect to early retirement were more likely to retire early, whereas persons with no partner were less likely to retire early. In the improved model, physical health was no longer related to the attitude of colleagues and supervisor about working until age 65, and developmental proactivity and financial situation of the household were no longer related to age discrimination. Having experienced a life event was significantly related to work engagement in the improved 


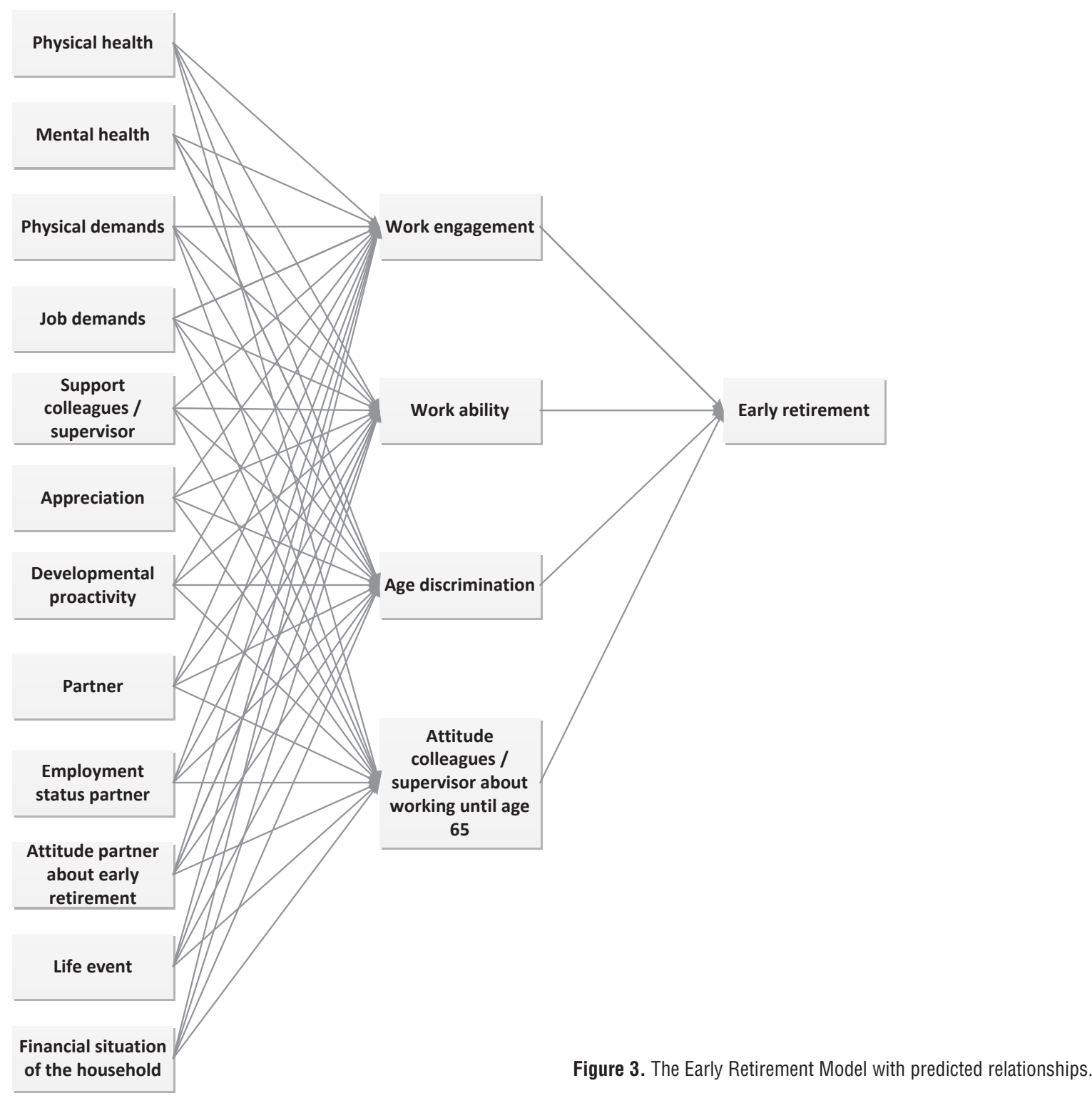

model, whereas this was not the case when testing the Early Retirement Model. The relations between all other variables in the improved model remained similar to those in the Early Retirement Model (maximum change in standardized $\beta=0.02$ ).

\section{Discussion}

The Early Retirement Model was largely supported by the data. Determinants in the domains health (poor physical health and poor mental health), job characteristics (high physical demands, low job demands, and low appreciation), skills and knowledge (low developmental proactivity), and social factors (positive attitude of the partner with respect to early retirement, and life events) influenced the transition from work to early retirement via lower work ability and less opportunity to work (more negative attitude of colleagues and supervisor about working until age 65). Improving the Early Retirement Model showed that high social support of colleagues and supervisor and a positive attitude of the partner with respect to early retirement also influenced early retirement directly, and that having a partner was only directly related to early retirement.

The finding that work ability and the opportunity to work mediate the relation between health, job characteristics, skills and knowledge, and social factors is in line with previous qualitative research $(14,22,23)$. Unexpectedly, work engagement did not mediate the relation between these determinants and early retirement, although previ- 
Table 1. Descriptives of the study population $(\mathrm{N}=1862)$. [SD=standard deviation]

\begin{tabular}{|c|c|c|c|}
\hline Characteristics & $\begin{array}{l}\text { Frequency } \\
\qquad \%)\end{array}$ & Mean & SD \\
\hline Age (58-62 years) & & 59.7 & 1.3 \\
\hline Gender (female) & 41 & & \\
\hline \multicolumn{4}{|l|}{ Educational level } \\
\hline Low & 29 & & \\
\hline Intermediate & 34 & & \\
\hline High & 37 & & \\
\hline Physical health $(1-100)^{\text {a }}$ & & 51.8 & 7.3 \\
\hline Mental health $(1-100)^{\text {a }}$ & & 53.8 & 7.1 \\
\hline Physical demands $(1-5)^{\text {a }}$ & & 1.7 & 0.8 \\
\hline Job demands $(1-5)^{\text {a }}$ & & 3.0 & 0.8 \\
\hline Support colleagues / supervisor (1-5) a & & 3.5 & 0.8 \\
\hline Appreciation (1-4) a & & 2.7 & 0.8 \\
\hline Developmental proactivity $(1-5)^{\text {a }}$ & & 3.9 & 0.6 \\
\hline Partner (no) ${ }^{b}$ & 24 & & \\
\hline $\begin{array}{l}\text { Attitude partner with respect to early } \\
\text { retirement }(1-5)^{c}\end{array}$ & & 3.4 & 0.9 \\
\hline Employment status partner (working) d & 44 & & \\
\hline Life event (yes) ${ }^{e}$ & 34 & & \\
\hline $\begin{array}{l}\text { Financial situation of the household } \\
(1-5)^{\text {a }}\end{array}$ & & 3.6 & 0.9 \\
\hline Work engagement $(1-7)^{\text {a }}$ & & 4.5 & 1.2 \\
\hline Work ability $(0-10)^{\text {a }}$ & & 7.9 & 1.5 \\
\hline Age discrimination $(1-5)^{\text {a }}$ & & 2.6 & 0.8 \\
\hline $\begin{array}{l}\text { Attitude colleagues and supervisor about } \\
\text { working until age } 65(1-5)^{c}\end{array}$ & & 3.2 & 0.8 \\
\hline Early retirement (yes) & 12 & & \\
\hline
\end{tabular}

a Higher score reflects better physical and mental health, higher physical demands, higher job demands, more appreciation at work, higher focus on development of knowledge and skills, better financial situation, higher work engagement, higher work ability, more age discrimination.

${ }^{\mathrm{b}}$ Higher score reflects having no partner.

c Higher score reflects more positive attitude of partner with respect to early retirement, more positive attitude of colleagues and supervisor about working until age 65 .

${ }^{\mathrm{a}}$ Higher score reflects the partner has a paid job.

${ }^{\mathrm{e}}$ Higher score reflects having experienced a life event.

ous qualitative research suggested this (14). In addition, a Dutch study showed that persons who were not willing to work until age 65 were more likely to retire early (47). It may be that we adopted a too limited operationalization of the motivation to work in the present study by focusing on work engagement. Actual work values and work motives may play a role as well. Besides, the motivation not to work, ie, to do things outside of work, may also need to be included in models and analyses. It might be that determinants, such as having a partner, attitude of the partner with respect to early retirement, and health, influence early retirement via a desire to enjoy life or spend more time with family (14) instead of the motivation to work. Although the domestic domain is also included in various other models that address early retirement (48, 49), the motivation to do things outside of work has not previously been included. Therefore, we recommend that future research investigates the mediating role of the motivation to do things outside work in addition to the ability, motivation and opportunity to work.
Previous research showed that a better psychosocial work environment, ie, more appreciation at work, decreased the likelihood of early retirement (17). However, in the present study, persons who reported higher social support of colleagues and supervisor were more likely to retire early. It may be that persons experience more support at work in case of important life events, eg, when approaching retirement. Therefore, we recommend future research to study within one dataset whether the strength of the association between support of colleagues and supervisor and early retirement depends on the period of time between the assessment of these variables. Another explanation could be that our measure on social support does not reflect how supportive a working environment is, but reflects support to persons experiencing life events that result in early retirement, eg, disease of their partner. Besides, in contradiction with previous research $(17,20,50)$, the financial situation of the household was not related to early retirement, neither directly nor indirectly. These contradictory findings might be explained by differences in the follow-up period and differences in the aspects of the financial situation that were assessed. We tested the latter possibility by post-hoc analyses in which we included the financial possibility to retire early ("Could you financially afford to stop working before the official retirement age?") (17) instead of the financial situation of the household. In line with our previous study (17), the financial possibility to retire had a direct influence on early retirement. Hence, different financial characteristics influence early retirement differently. Future research needs to further clarify which aspects of the financial domain are of importance with respect to early retirement.

Favorable early retirement schemes were still widely accessible in the Netherlands at the time of data collection, whereas labor market opportunities were limited. These circumstances may have influenced our findings. Favorable retirement arrangements will decline in the near future, eg, due to the official retirement age increasing from 65 years in 2012 to 67 years in 2023 (3). At the same time, due to the extensive public debate on the need to prolong working life, the social norm at work may become more favorable with respect to prolonged careers. In the present study, this importantly contributed to early retirement. Hence, we expect that increasing job opportunities for older workers may strongly contribute to the prolongation of working life.

A strength of the present study is that we addressed not only determinants of early retirement but also mediating variables and, hence, underlying mechanisms. In addition, determinants, mediating variables and early retirement were measured at separate moments in time in a longitudinal study. Another strength is that variables frequently studied in different areas of expertise, ie, health, job characteristics, skills and knowledge, 
Table 2. Early Retirement Model, standardized betas. Bold indicates associations with $\mathrm{P}<0.05$.

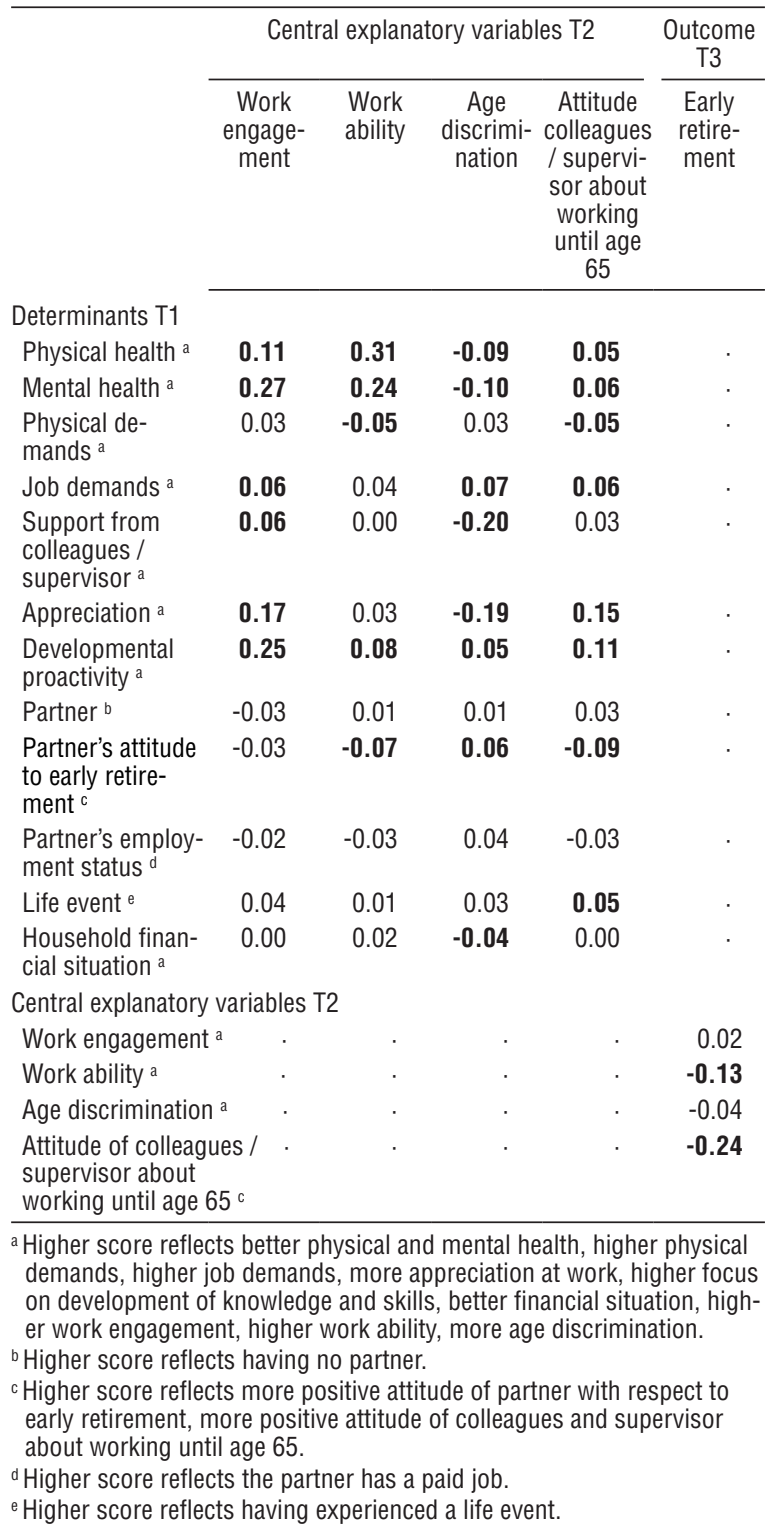

social and financial factors, work ability, motivation and opportunity to work, were incorporated in one study. However, this study also has limitations. First, the results are likely to be influenced by the operationalization of the variables in this study. As already mentioned, this may be true for the operationalization of the motivation to work and financial factors. Moreover, the operationalization of the opportunity to work by means of age discrimination and the attitude of colleagues and supervisor about working until age 65 reflect the opportunities to work within the work organization. This could be supplemented with labor market opportunities in general, which may also play an important role in early retirement (14). A second limitation is the rela-
Table 3. Improved model, standardized betas.

\begin{tabular}{|c|c|c|c|c|c|}
\hline & \multicolumn{4}{|c|}{ Central explanatory variables T2 } & \multirow{2}{*}{$\begin{array}{l}\text { Outcome } \\
\text { T3 } \\
\text { retirement } \\
\text { tarly }\end{array}$} \\
\hline & $\begin{array}{l}\text { Work } \\
\text { engage- } \\
\text { ment }\end{array}$ & $\begin{array}{l}\text { Work } \\
\text { ability }\end{array}$ & $\begin{array}{l}\text { Age dis- } \\
\text { crimina- } \\
\text { tion }\end{array}$ & $\begin{array}{c}\text { Attitude } \\
\text { col- } \\
\text { leagues / } \\
\text { supervi- } \\
\text { sor about } \\
\text { working } \\
\text { until age } \\
65 \\
\end{array}$ & \\
\hline \multicolumn{6}{|l|}{ Determinants $\mathrm{T} 1$} \\
\hline Physical health a & 0.11 & 0.31 & -0.09 & . & . \\
\hline Mental health a & 0.27 & 0.24 & -0.10 & 0.05 & . \\
\hline Physical demands a & & -0.05 & & -0.06 & . \\
\hline Job demands a & 0.05 & . & 0.09 & 0.05 & . \\
\hline $\begin{array}{l}\text { Support from } \\
\text { colleagues / } \\
\text { supervisor a }\end{array}$ & 0.05 & . & -0.19 & . & 0.14 \\
\hline Appreciation a & 0.17 & . & -0.18 & 0.16 & . \\
\hline $\begin{array}{l}\text { Developmental } \\
\text { proactivity a }\end{array}$ & 0.26 & 0.09 & . & 0.13 & . \\
\hline Partner ${ }^{b}$ & . & . & . & . & -0.13 \\
\hline $\begin{array}{l}\text { Partner's attitude to } \\
\text { early retirement c }\end{array}$ & . & -0.05 & 0.05 & -0.08 & 0.15 \\
\hline $\begin{array}{l}\text { Partner's employ- } \\
\text { ment status }{ }^{d}\end{array}$ & . & . & . & . & . \\
\hline Life event $\mathrm{e}$ & 0.04 & . & . & 0.05 & . \\
\hline $\begin{array}{l}\text { Financial situation of } \\
\text { the household a }\end{array}$ & . & . & . & . & . \\
\hline \multicolumn{6}{|c|}{ Central explanatory variables T2 } \\
\hline Work engagement ${ }^{\mathrm{a}}$ & & . & . & . & \\
\hline Work ability a & . & . & . & . & -0.12 \\
\hline Age discrimination a & . & . & 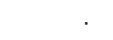 & . & \\
\hline $\begin{array}{l}\text { Attitude of colleagues / } \\
\text { supervisor about } \\
\text { working until age } 65\end{array}$ & / & . & . & . & -0.23 \\
\hline \multicolumn{6}{|c|}{$\begin{array}{l}\text { a Higher score reflects better physical and mental health, higher physical } \\
\text { demands, higher job demands, more appreciation at work, higher focus } \\
\text { on development of knowledge and skills, better financial situation, high- } \\
\text { er work engagement, higher work ability, more age discrimination. } \\
\text { b Higher score reflects having no partner. }\end{array}$} \\
\hline \multirow{2}{*}{\multicolumn{6}{|c|}{$\begin{array}{l}\text { ' Higher score reflects more positive attitude of partner with respect to } \\
\text { early retirement, more positive attitude of colleagues and supervisor } \\
\text { about working until age } 65 \text {. } \\
{ }^{\mathrm{d}} \text { Higher score reflects the partner has a paid job. }\end{array}$}} \\
\hline & & & & & \\
\hline${ }^{\mathrm{e}}$ Higher score reflects he & naving ex & no & fe e & nl) & \\
\hline
\end{tabular}

tively short follow-up period of two years in the present study. Moreover, the time periods between determinants and central explanatory variables and between central explanatory variables and early retirement were fixed to one year. To capture the complete pre-retirement process, a longer follow-up period may be needed. Besides, future research needs to shed light on the time windows of different underlying mechanisms, eg, from poor health to reduced work ability, to early retirement. Third, our study population participated in the internet panel. Although $97 \%$ of the persons aged $12-65$ and $74 \%$ of those aged $65-75$ years use the internet in the Netherlands (51), generalizability of our findings to certain vulnerable groups may be limited, eg, illiterate 
persons, persons who do not master the Dutch language and those without internet access. Fourth, we found some differences in baseline characteristics between participants and persons lost to follow-up. Although these differences were small, bias due to non-response at follow-up cannot be ruled out. Fifth, the standardized betas in the present study are relatively small. However, we believe they are meaningful. SEM deals simultaneously with multiple relationships between several variables, and hence, all associations are corrected for overlap with other variables. Taking that into account, we think the standardized betas in our study are of moderate size. Sixth, in our SEM analysis a large number of associations was estimated simultaneously. As the risk of obtaining a false significant association is $\alpha=0.05$ for each individual association, it is possible that some of our significant associations were false positive, as in all analyses with multiple parameters tested. Finally, differences between subgroups of employees, eg, different occupations, could not be presented due to a lack of statistical power. However, we did perform an additional multi-group analysis to examine the Early Retirement Model among employees with different educational levels. Relations between variables appeared roughly similar among employees with low-, intermediate- and high-education levels. We recommend future studies with sufficient statistical power to investigate differences between other subgroups of employees.

As previously described, future research is needed to improve the operationalization of the motivation and opportunity to work, study persons for a longer period of time, and investigate differences among subgroups of workers. Besides, it would be of interest to study additional determinants in the Early Retirement Model. For example, we recommend future research to include information on (the availability of) early retirement schemes and private savings for retirement in order to gain insight in their impact on early retirement. In addition, within the domain of social factors, the influence of having co-resident children and providing informal care could be addressed. Finally, we recommend future research to study mechanisms underlying early retirement in different countries to investigate whether similar determinants and mechanisms play a role in countries with different pension systems.

In conclusion, the Early Retirement Model was largely supported by the data, but could be further improved. Work ability and the opportunity to work provided within the work organization (ie, the social norm with respect to early retirement) mediated the relation between health, job characteristics, skills and knowledge, and social factors, on the one hand, and early retirement on the other hand. Hence, increasing work ability and job opportunities within work organizations may contribute to the prolongation of working life. In the present study, these mediating variables were importantly influenced by health, appreciation at work, and developmental proactivity. Therefore, workplace health promotion, interventions improving the social climate at work, and designing jobs in such a way that employees are continuously stimulated to expand their skills and knowledge and adapt to changes in their work may support employees to work until older age. It should be noted that factors in the domestic domain, ie, the attitude of the partner with respect to early retirement and life events, also contributed to early retirement. These are factors that cannot be influenced directly by workplace interventions. Finally, the results of the present study indicate that various determinants and mechanisms underlie early retirement, and hence, that policies, regulations and interventions that aim to prolong working life need to cover a diversity of factors and need to be tailored to the individual employee.

\section{Acknowledgments}

The current study was conducted with financial support from the Ministry of Social Affairs and Employment in the Netherlands.

\section{References}

1. European Commission. De demografische toekomst van Europa: probleem of uitdaging? [The demographic future of Europe - From challenge to opportunity]. Brussels, Belgium: Commission of the European Communities; 2006.

2. Rijksoverheid. The old age pension system in the Netherlands. The Netherlands, The Hague: Rijksoverheid; 2008.

3. Rijksoverheid. Future pension system. Available from: http:// www.rijksoverheid.nl/onderwerpen/pensioen/toekomstpensioenstelsel. Accessed November 29, 2013.

4. Rijksoverheid. What is VUT and prepensioen? Available from: http://www.rijksoverheid.nl/onderwerpen/pensioen/vraagen-antwoord/wat-is-vut-en-prepensioen.html. Accessed July $30,2014$.

5. Conen WS, Henkens K, Schippers J. Employers' attitudes and actions towards the extension of working lives in Europe. Int J Manpow. 2012;33(6):648-65. http://dx.doi. org/10.1108/01437721211261804

6. Oeij P, de Vroome EMM, Kraan K, Goudswaard A, van den Bossche S. Werkgevers Enquete Arbeid 2012: Methodologie en beschrijvende resultaten [Netherlands Employers Work Survey 2012: Methodology and descriptive results]. Hoofddorp, the Netherlands: TNO Innovation for life; 2013.

7. OECD. Ageing and Employment Policies: Netherlands 2014: Working Better with Age : OECD Publishing; 2014. 
8. van Rijn RM, Robroek SJ, Brouwer S, Burdorf A. Influence of poor health on exit from paid employment: a systematic review. Occup Environ Med. 2014 Apr;71(4):295-301. http:// dx.doi.org/10.1136/oemed-2013-101591.

9. van den Berg TIJ, Elders LAM, Burdorf A. Influence of health and work on early retirement. J Occup Environ Med. 2010;52(6):576-83. http://dx.doi.org/10.1097/ JOM.0b013e3181de8133.

10. Karpansalo M, Kauhanen J, Lakka TA, Manninen P, Kaplan GA, Salonen JT. Depression and early retirement: Prospective population based study in middle aged men. J Epidemiol Community Health. 2005;59(1):70-4. http:// dx.doi.org/10.1136/jech.2003.010702.

11. Lund T, Iversen L, Poulsen KB. Work environment factors, health, lifestyle and marital status as predictors of job change and early retirement in physically heavy occupations. Am J Ind Med. 2001;40(2):161-9. http://dx.doi.org/10.1002/ ajim. 1084 .

12. Blekesaune $M$, Solem PE. Working conditions and early retirement: A prospective study of retirement behavior. Res Aging. 2005;27(1):3-30. http://dx.doi. org/10.1177/0164027504271438.

13. Friis K, Ekholm O, Hundrup YA, Obel EB, Grønbæk M. Influence of health, lifestyle, working conditions, and sociodemography on early retirement among nurses: The Danish nurse cohort study. Scand J Public Health. 2007;35(1):23-30. http://dx.doi.org/10.1080/14034940600777278.

14. Reeuwijk KG, de Wind A, Westerman MJ, Ybema JF, van der Beek AJ, Geuskens GA. 'All those things together made me retire': qualitative study on early retirement among Dutch employees. BMC Public Health. 2013 May 28;13(1):516. http://dx.doi.org/10.1186/1471-2458-13-516.

15. Damman M, Henkens K, Kalmijn M. The impact of midlife educational, work, health, and family experiences on men's early retirement. J Gerontol Ser B Psychol Sci Soc Sci. 2011;66 B(5):617-27.

16. Herrbach O, Mignonac K, Vandenberghe C, Negrini A. Perceived HRM practices, organizational commitment, and voluntary early retirement among late-career managers. Hum Resour Manage. 2009;48(6):895-915. http://dx.doi. org/10.1002/hrm.20321.

17. de Wind A, Geuskens GA, Ybema JF, Blatter BM, Burdorf A, Bongers PM, et al. Health, job characteristics, skills, and social and financial factors in relation to early retirement-results from a longitudinal study in the Netherlands. Scand J Work Environ Health. 2014 Mar;40(2):186-94. http://dx.doi. org/10.5271/sjweh.3393.

18. Henkens $K$, van Dalen $H$, van Solinge H. De vervagende grens tussen werk en pensioen. Over doorwerken, doorstarten en herintreders [The fading border between employment and retirement. About continuing to work and re-entering employment]. Den Haag, the Netherlands: NIDI; 2009.

19. Fischer JAV, Sousa-Poza A. The institutional determinants of early retirement in Europe. London: Department of Economics, University of St. Gallen; 2006.
20. Proper KI, Deeg DJH, van der Beek A. Challenges at work and financial rewards to stimulate longer workforce participation. Human Resources for Health. 2009;7:70. http://dx.doi. org/10.1186/1478-4491-7-70.

21. Schultz KS, Morton KR, Weckerle JR. The Influence of Push and Pull Factors on Voluntary and Involuntary Early Retirees' Retirement Decision and Adjustment. J Vocat Behav. 1998;53(1):45-57. http://dx.doi.org/10.1006/ jvbe.1997.1610.

22. Pond R, Stephens C, Alpass F. How health affects retirement decisions: Three pathways taken by middle-older aged New Zealanders. Ageing and Society. 2010;30(3):527-45. http:// dx.doi.org/10.1017/S0144686X09990523.

23. de Wind A, Geuskens GA, Reeuwijk KG, Westerman MJ, Ybema JF, Burdorf A, et al. Pathways through which health influences early retirement: a qualitative study. BMC Public Health. 2013 Apr 3;13:292. http://dx.doi.org/10.1186/14712458-13-292.

24. Ybema JF, Geuskens GA, van den Heuvel SG, de Wind A, Leijten FRM, Joling C, et al. Study on Transitions in Employment, Ability and Motivation (STREAM): The design of a four-year longitudinal cohort study among 15,118 persons aged 45 to 64 years. Br J Med Med Res. 2014;4(6):1383-99. http://dx.doi.org/10.9734/BJMMR/2014/7161.

25. Ilmarinen J. Work ability - a comprehensive concept for occupational health research and prevention. Scand J Work Environ Health. 2009 Jan;35(1):1-5. http://dx.doi. org/10.5271/sjweh.1304.

26. Ahlstrom L, Grimby-Ekman A, Hagberg M, Dellve L. The work ability index and single-item question: Associations with sick leave, symptoms, and health - A prospective study of women on long-term sick leave. Scand J Work Environ Health. 2010;36(5):404-12. http://dx.doi.org/10.5271/sjweh.2917.

27. Gamperiene M, Nygård JF, Sandanger I, Lau B, Bruusgaard D. Self-reported work ability of Norwegian women in relation to physical and mental health, and to the work environment. J Occup Med Toxicol. 2008;3(1). http://dx.doi. org/10.1186/1745-6673-3-8.

28. Leijten FR, van den Heuvel SG, Ybema JF, van der Beek AJ, Robroek SJ, Burdorf AA. The influence of chronic health problems on work ability and productivity at work: a longitudinal study among older employees. Scand J Work Environ Health. 2014 Sep 1;40(5):473-82. http://dx.doi. org/10.5271/sjweh.3444.

29. Sell L, Bültmann U, Rugulies R, Villadsen E, Faber A, Søgaard K. Predicting long-term sickness absence and early retirement pension from self-reported work ability. Int Arch Occup Environ Health. 2009;82(9):1133-8. http://dx.doi. org/10.1007/s00420-009-0417-6.

30. Hakanen JJ, Schaufeli WB, Ahola K. The job demandsresources model: A three-year cross-lagged study of burnout, depression, commitment, and work engagement. Work Stress. 2008;22(3):224-41. http://dx.doi. org/10.1080/02678370802379432.

31. Schaufeli WB, Bakker AB, van Rhenen W. How changes in 
job demands and resources predict burnout, work engagement, and sickness absenteeism. J Organ Beha. 2009;30(7):893-917. http://dx.doi.org/10.1002/job.595.

32. Schreurs B, de Cuyper N, van Emmerik IJH, Notelaers G, de Witte H. Job demands and resources and their associations with early retirement intentions through recovery need and work enjoyment. SA J Ind Psychol. 2011;37(2).

33. van den Berg TIJ, Schuring M, Avendano M, Mackenbach J, Burdorf A. The impact of ill health on exit from paid employment in Europe among older workers. Occup Environ Med. 2010;67(12):845-52. http://dx.doi.org/10.1136/ oem.2009.051730.

34. Ware Jr. JE, Kosinski M, Keller SD. A 12-Item Short-Form Health Survey: Construction of Scales and Preliminary Tests of Reliability and Validity. Med Care. 1996;34(3):220-33. http:// dx.doi.org/10.1097/00005650-199603000-00003.

35. Koppes L, de Vroome E, Mol M, Janssen B, van den Bossche S. Nationale Enquête Arbeidsomstandigheden 2008: Methodologie en globale resultaten [The Netherlands Working Conditions Survey 2008: Methodology and overall results]. Hoofddorp, the Netherlands: TNO; 2009.

36. Hildebrandt VH, Bongers PM, van Dijk FJ, Kemper HC, Dul J. Dutch Musculoskeletal Questionnaire: description and basic qualities. Ergonomics. 2001 Oct 10;44(12):1038-55. http:// dx.doi.org/10.1080/00140130110087437.

37. Karasek R. Job Content Questionnaire and User's Guide. Lowell: University of Massachusetts, Department of work environment; 1985.

38. Karasek R, Brisson C, Kawakami N, Houtman I, Bongers P, Amick B. The Job Content Questionnaire (JCQ): an instrument for internationally comparative assessments of psychosocial job characteristics. J Occup Health Psychol. 1998;3(4):32255. http://dx.doi.org/10.1037/1076-8998.3.4.322.

39. Kristensen TS, Hannerz H, Høgh A, Borg V. The Copenhagen Psychosocial Questionnaire - A tool for the assessment and improvement of the psychosocial work environment. Scand J Work Environ Health. 2005;31(6):438-49. http://dx.doi. org/10.5271/sjweh.948.

40. van Veldhoven M, Dorenbosch L. Age, proactivity and career development. Career Development International. 2008;13(2):112-31. http://dx.doi. org/10.1108/13620430810860530.

41. Cohen J, Cohen P. Applied multiple regression / correlation analysis for the behavioral sciences. 2nd ed. New Jersey: Lawrence Erlbaum Associates; 1983.
42. Schaufeli WB, Bakker AB, Salanova M. The measurement of work engagement with a short questionnaire: A cross-national study. Educational and Psychological Measurement. 2006;66(4):701-716. http://dx.doi. org/10.1177/0013164405282471.

43. Furunes T, Mykletun R. Age discrimination in the workplace: Validation of the Nordic Age Discrimination Scale (NADS). Scand J Psychol. 2010;51:23-30. http://dx.doi.org/10.1111/ j.1467-9450.2009.00738.x.

44. Boomsma A, Hoogland J. The robustness of LISREL modeling revisited. In: R Cudeck, S du Toit \& D Sörbom, editors. Structural equation models: Present and future. A Festschrift in honor of Karl Jöreskog Lincolnwood, IL: Scientific Software International; 2001. p. 139-68.

45. Hooper D, Coughlan J, Mullen MR. Structural equation modelling: Guidelines for determining model fit. Electronic Journal of Business Research Methods. 2008;6(1):53-60.

46. Hu LT, Bentler PM. Fit Indices in Covariance Structure Modeling: Sensitivity to Underparameterized Model Misspecification. Psychol Methods. 1998;3(4):424-53. http:// dx.doi.org/10.1037/1082-989X.3.4.424.

47. Ybema JF, Geuskens GA, Oude Hengel KM. Oudere werknemers en langer doorwerken [Older employees and prolonging working life]. Hoofddorp: TNO; 2009.

48. Peter R, Hasselhorn HM. Work, age, health, and work participation: A theoretical model. Bundesgesundheitsblatt Gesundheitsforschung - Gesundheitsschutz 2013;56(3):41521. http://dx.doi.org/10.1007/s00103-012-1615-z.

49. Kubicek B, Korunka C, Hoonakker P, Raymo JM. Work and family characteristics as predictors of early retirement in married men and women. Res Aging. 2010;32(4):467-98. http://dx.doi.org/10.1177/0164027510364120.

50. Crawford R, Tetlow G. Employment, retirement and pensions. In: Banks J, Lessof C, Nazroo J, Rogers N, Stafford M, Steptoe A, editors. Financial circumstances, health and wellbeing of the older population in England - The 2008 English Longitudinal Study of Ageing (Wave 4) London: The Institute for Fiscal Studies; 2010. p. 11-75.

51. Centraal Bureau voor de Statistiek. Internetgebruik van personen vanaf 12 jaar [Intenet usage by persons 12 years or older]. 2012; Available from: http://www.cbs.nl/nl-NL/ menu/themas/vrije-tijd-cultuur/publicaties/artikelen/ archief/2013/2013-3834-wm.htm. Accessed July 30, 2014.

Received for publication: 27 January 2014 